particularly common in Bristol. Motor accidents caused a significant number of all the deaths from external sources.

The survey concludes with possible numbers of deaths which could have been prevented. Males are more likely than females to die from alcoholism and external causes, and over half the deaths for men under 35 are thought to be preventable. For women under 35 the figure is just about half. In the $35-54$ age group these figures fall to around 40 per cent for both sexes and in the 55-74 group they fall again to $20-30$ per cent. A significant number of female deaths are attributable to pregnancy and childbirth, and, of these, abortions form a substantial, and preventable part. The situation in country districts of South America, where shortage of medical facilities is thought to be responsible for the high mortality rates of young adults, is one which can be changed.

\section{Less Discrimination}

RACIAL discrimination in Britain was described in a report sponsored by PEP (Political and Economic Planning) and published in April this year. Further legislation was thought to be necessary and the Race Relations Board has now sponsored a complementary report which would be a guide for Government action in extending the 1965 Race Relations Act. Professor Harry Street, Mr Geoffrey Howe and Mr Geoffrey Bindman have made a thorough investigation of antidiscrimination legislation in countries other than Britain, assessed its effectiveness and considered what types of legislation would be most suitable for Britain. Their findings (Anti-Discrimination Legislation, The Street Report) are published this week by PEP.

Much has been learned from legislation in the United States on discrimination which has often been too little and too late. To prevent inequality becoming entrenched in British society, the Street Report proposes widespread extension of the present act to cover all aspects of public life and a large proportion of private transactions. Employment, housing, government contracts, insurance and all services from shops and repairs to those of professional people should, it says, be added to the present list of public buildings, transport and entertainment. Crown and government employment should be included except where national security questions have to be considered. Small units of housing or employment where family relationships are involved are the only cases recommended as exceptions to the law. Owner occupied houses are thought to be such a fundamental part of family life that legislation against discrimination in sales of such properties is thought to be a political question, and the report, without a unanimous decision, hands the matter to the Government.

Discrimination on factors of race, colour and ethnic or national origin is the basis of the legislation, but religious discrimination should not be included. It is emphasized that legislation alone will not be enough. Wholehearted government backing must be given to ensure that the law is enforced efficiently, and that justice is seen to be done. Education programmes are essential to show the public the importance of an integrated society. The report suggests that the structure of the Race Relations Board and its local conciliation committees should be strengthened to put these proposals into effect, and the powers of the board should be extended. The board should be able to issue subpoenas, but their orders should only be enforceable through the courts. Conciliation is the key word in discrimination proceedings, but a tribunal should be set up for cases where it fails. There should be no question of criminal penalties for unlawful discrimination, but failure to comply with decisions could result in proceedings for contempt of court.

\section{Heat and Sound}

Professor Eigen, who shares the Nobel Prize for Chemistry, has worked closely in collaboration with L. deMaeyer at Gottingen and has introduced and developed a technique for following the kineties of very rapid reactions in solution and has worked on both the theory and practice of reactions ranging from $0 \cdot 1$ sec, down to almost the limit of chemical reactions.

The principal difficulty in studying fast reactions is bringing the reactants together in a sufficiently short time. That is, the mixing time must be less than the reaction time. Professor Eigen's solution is to take a system in equilibrium and to subject it to a disturbance in the external parameter such as temperature, pressure or electric field strength. This changes the position of the equilibrium but sometimes the position is not readjusted as soon as the external conditions have been changed: that is, there is a time lag. The displacement from equilibrium is measured spectrophotometrically or by conductivity. It is a first order process and the reciprocal of the rate constant is the relaxation time. The latter is a composite function of the rate constants of the elementary steps occurring in the reacting system. By analysing chemical relaxation (the difference between "internal" and "external" conditions) under different conditions, intimate details of chemical reactions in the system can be studied.

There are two particular techniques. The first is a stationary method of analysis using, for example, ultrasonics: the second is a transient method using temperature jump. The latter is the more versatile and best developed but it does not measure the fastest techniques. Chemical relaxation is important because it has opened up a vast new range of chemical reactions for kinetic studies. It was originally used for very fast inorganic studies such as proton transfer and metal complex formation in water. In the last few years, however, attention has been focused on reactions of biological importance; for example, enzyme-substrate reactions, muscle contraction and protein synthesis. It can also be used to follow DNA replication reactions-one base pair replication of DNA must occur at least every $10^{-3}$ sec. Eigen's main interest now lies in this biophysical field and he is to have the use of a new Max--Planck institute which will be opened in three years.

\section{Flashing Lights}

THe award of a half-share in the Nobel Prize for Chemistry to Professors R. G. W. Norrish and George Porter is reckoned to be a fitting recognition of twenty years of careful work by two talented experimenters. Professor Norrish retired two years ago as professor of physical chemistry at Cambridge, but remains actively 
at work at the laboratories. Professor Porter was a research student at Cambridge after the Second World War, and it was there that he and Professor Norrish began work on the development of flash photolysis as a technique for the study of extremely fast chemical reactions, usually by the intermediary of unstable molecular species. In 1955 he moved to Sheffield as professor of chemistry and then, a year ago, to the Royal Institution as director.

It is probably fair to say that Nobel Prizes are of two kinds - those awarded for discoveries of an im. mediate character, and those awarded for the opening up of a new field of investigation, which usually entails the development of a new technique. This is a Nobel Prize of the second kind, and is in this sense comparable to the award of Nobel Prizes in the past for the development of techniques such as the use of photographic emulsions for the measurement of cosmic rays and the study of nuclear reactions or for the application of X-ray diffraction analysis to the definition of tertiary structure in proteins. Not merely is flash photolysis as such a difficult technique, but its full value is only realizable now that there is a sufficient body of information available for the interpretation of results to be fairly straightforward and unambiguous. What Professors Norrish and Porter have done may well be described as the founding of a novel kind of chemistry.

Over the years, the duration of the pulses of light energy used for the irradiation of a sample of material has decreased from a millisecond to a microsecond, and the arrival of lasers has made it likely that there will now be a further compression of the time-scale. At the same time, energy output has steadily increased, with the result that 1,000 Joules may be fed through a light source in one pulse and that chemistry laboratories are made to seem even more like thermonuclear research establishments, with banks of capacitors accumulating charge. Perhaps the most tangible benefit so far is that it is now possible to observe directly the properties of some of the unstable molecular species which are assumed to play a part in chemical reactions. Now that Professor Porter has turned his interest to the study of flash photolysis in liquids and solutions, the harvest of innovation will no doubt be even more diverse.

\section{Nuclear Reactions}

Professor Hans Bethe, who is awarded the Nobel Prize for Physics for 1967, is one of the most productive of Grand Old Men. He has been a prolific source of innovation in theoretical physics since the early thirties, and although the Nobel Committee has singled out for special mention his identification (in 1938) of the nuclear reactions most probably responsible for the output of stellar energy, this represents only a very small part of his output.

Professor Bethe, who is 61 , left Germany for the United States in 1935, and was by then distinguished for his versatility. His review articles on the theory of metals and of nuclear reactions-the latter published in 1937-are models of their kind (and still topical enough to be re-edited and republished). His first pieces of theoretical physics were concerned with the motion of electrons in solids, and were carried out in collaboration with Professor A. Sommerfeld. In the early thirties he made a monumental contribution (with Heitler) by calculating the electrodynamics of electron-positron pair production. His contributions to nuclear physics proper began in 1934 with some calculations of nucleon-nucleon scattering, and by 1936 he was deeply involved in the scattering of nuclear particles from multi-nucleon nuclei. Bethe was one of the first to make calculations with the meson field as a means of mediating nuclear interactions.

Bethe's paper on the thermonuclear energy of stars may seem almost to be a by-product of the remainder of his activity. By the late thirties, the problem was to identify which nuclear reactions could realistically be supposed to contribute to the energy production in stars. Bethe picked out two possible sequences of reactions by which hydrogen may be converted into helium-that which involves the successive additions of protons to a proton to form helium-3 followed by the interaction of two helium-3 nuclei to form one of helium-4, and that which involves a shuttling of protons between the isotopes of carbon and nitrogen. At the time it seemed as if the carbon-nitrogen cycle would be the chief source of thermonuclear energy in stars. Now it is more probable that the direct sequence of events is the more important.

Bethe has been a public figure as well as a physicist. After his stint at Los Alamos, he returned to Cornell University and has since been unafraid to involve himself in the Oppenheimer hearing (where, it is true, he had no option) and in public discussion about such issues as the feasibility of technical methods of disarmament-the detection of underground explosions, for example.

\section{Striking a Balance}

SCIENCE and technology have not yet swept the board in the schools with innovations of the curriculum. Members of the Group for Educational Services in Museums have now launched a service designed to bring young people to a closer understanding of their place in history.

The service will function in several ways. First, it will provide facilities for teachers and students to make use of collections in museums. These will cover art, geography, history and natural history. Second, it will organize regular loan distribution of museum objects for schools. Finally, the service will organize miscellaneous activities such as lectures and clubs. Two patterns of organization are in operation. One is based on county boroughs or borough museums administered by a committee of the authority and financed by grants from the local education authorities. The other, the county service, may or may not be based on a county museum, but is financed chiefly or wholly by the county education committee. Sometimes a service may also have an advisory committee consisting of teachers or schools inspectors. All the services are in the charge of a school officer who is responsible to the chief officer of the museum or education committee for detailed administration of the departments.

Organization will depend to a large extent on the particular area. Thus rural areas will have a greater need of a loan service than will better equipped urban areas, and the cost will be higher. The character of an area will also be reflected in the line of study: for 